\title{
Dendritic Cells in Human Atherosclerosis: From Circulation to Atherosclerotic Plaques
}

\author{
Emily A. Van Vré, ${ }^{1}$ Ilse Van Brussel, ${ }^{1}$ Johan M. Bosmans, ${ }^{1}$ \\ Christiaan J. Vrints, ${ }^{1}$ and Hidde Bult ${ }^{2}$
${ }^{1}$ Division of Cardiology, Department of Translational Pathophysiological Research, Faculty of Medicine, University of Antwerp, 2610 Wilrijk, Belgium
${ }^{2}$ Division of Pharmacology, Department of Translational Pathophysiological Research, Faculty of Medicine, University of Antwerp, 2610 Wilrijk, Belgium

Correspondence should be addressed to Hidde Bult, hidde.bult@ua.ac.be

Received 11 May 2011; Accepted 31 July 2011

Academic Editor: Freek Zijlstra

Copyright ( $) 2011$ Emily A. Van Vré et al. This is an open access article distributed under the Creative Commons Attribution License, which permits unrestricted use, distribution, and reproduction in any medium, provided the original work is properly cited.

\begin{abstract}
Background. Atherosclerosis is a chronic inflammatory disease with atherosclerotic plaques containing inflammatory infiltrates predominantly consisting of monocytes/macrophages and activated T cells. More recent is the implication of dendritic cells (DCs) in the disease. Since DCs were demonstrated in human arteries in 1995, numerous studies in humans suggest a role for these professional antigen-presenting cells in atherosclerosis. Aim. This paper focuses on the observations made in blood and arteries of patients with atherosclerosis. In principal, flow cytometric analyses show that circulating myeloid $(\mathrm{m})$ and plasmacytoid $(\mathrm{p})$ DCs are diminished in coronary artery disease, while immunohistochemical studies describe increased intimal DC counts with evolving plaque stages. Moreover, mDCs and pDCs appear to behave differently in atherosclerosis. Yet, the origin of plaque DCs and their relationship with blood DCs are unknown. Therefore, several explanations for the observed changes are postulated. In addition, the technical challenges and discrepancies in the research field are discussed. Future. Future studies in humans, in combination with experimental animal studies will unravel mechanisms leading to altered blood and plaque DCs in atherosclerosis. As DCs are crucial for inducing but also dampening immune responses, understanding their life cycle, trafficking and function in atherosclerosis will determine potential use of DCs in antiatherogenic therapies.
\end{abstract}

\section{Introduction}

Atherosclerosis takes a huge toll on our society. It is the leading cause of morbidity and mortality in the Western world, and growing incidence of atherosclerosis-related diseases has also been recently observed in developing countries [1]. It has become evident that inflammation mediated both by innate and adaptive immunity plays an important role even in the earliest stages of the development of atherosclerotic lesions $[2,3]$.

Dendritic cells (DCs) constitute a family of professional antigen-presenting cells that have the unique ability to induce primary T-cell responses. Moreover, they are not only essential in launching immune reactions against harmful antigens, but also in maintaining immune tolerance $[4,5]$.
As key modulators of immune responses, they are likely to play a crucial role in directing innate or adaptive immunity against altered self-antigens present in atherosclerosis, such as oxidized epitopes on apoptotic cells, oxidized low-density lipoproteins (oxLDL), or heat shock proteins (Hsp) [6].

As illustrated in Figure 1, the general concept on the life cycle of DCs involves three stages. They originate from haematopoietic stem cells in the bone marrow and circulate as precursors in the blood stream, taking residence in target tissues at sites of potential antigen entry. Within these tissues, they give rise to immature interstitial DCs that act as sentinels, which continuously and efficiently sample the antigenic content of their microenvironment. In the steady state, immature DCs capture harmless selfantigens in the absence of inflammatory signals. They might 
General life cycle of DCs

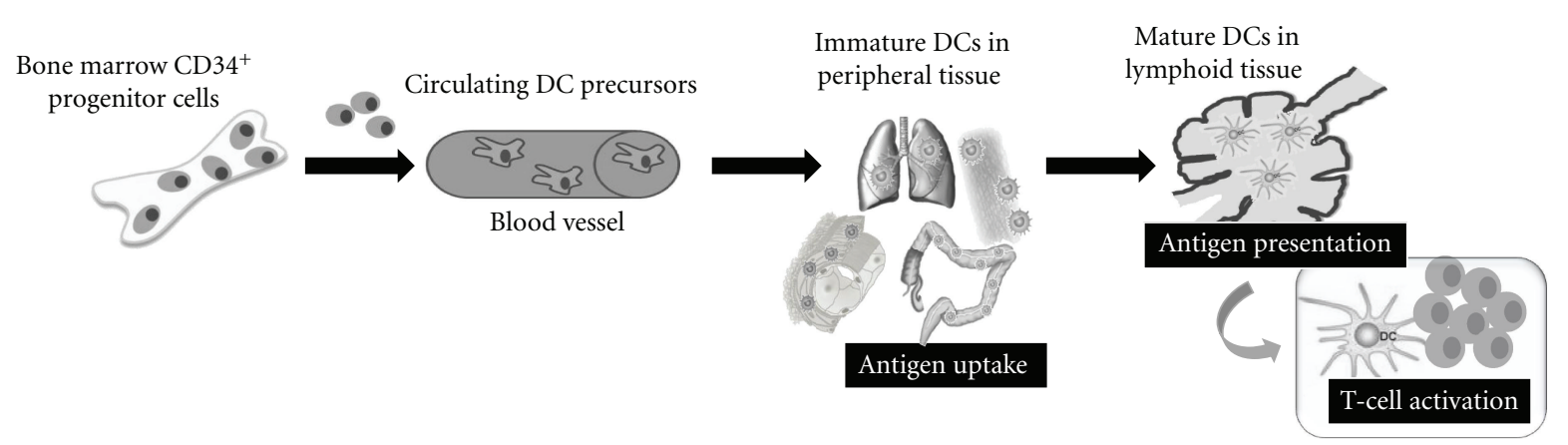

FIGURE 1: Schematic presentation of life cycle of DCs.

enter the regional lymph nodes to present the self-antigen to naïve or resting $\mathrm{T}$ cells, which will be deleted by the induction of apoptosis, silenced by the induction of anergy or primed to become regulatory $\mathrm{T}$ cells [4]. In contrast, when infection and tissue damage occurs, immature DCs take up antigens in the presence of inflammatory signals, which cause activation and functional transformation into mature DCs, thereby downregulating endocytotic capacity and upregulating chemokine receptors (e.g., CCR-7), adhesion (e.g., CD50) and activation molecules needed for antigen presentation (e.g., CD83, CD86) [4, 5]. Meanwhile they exit the nonlymphoid tissues to migrate via afferent lymph to lymphoid tissues (lymph nodes or spleen), where they complete maturation. Mature DCs will present short peptide fragments, which are bound to the surface molecules CD1 or major histocompatibility complex- (MHC-) I or MHC-II. Consequently, they will activate (naïve) $\mathrm{T}$ and $\mathrm{B}$ lymphocytes that recognize the presented antigen $[5,7-9]$.

The present review is aimed at summarizing current knowledge of the role of DCs in the pathogenesis of human atherosclerosis: from circulating DC precursors in patients with coronary artery disease (CAD) to DCs found in human atherosclerotic lesions. Technical challenges and open questions in this research field are discussed in detail.

\section{Circulating DCs in CAD}

2.1. Subtypes of Blood DC Precursors. Two main DC precursor subtypes can be identified in human blood: myeloid (m)DCs and plasmacytoid (p)DCs. As DC precursors they are relatively immature and express only low levels of adhesion and costimulatory molecules-at least in physiological conditions [10-12]. mDCs (0.26\% among leukocytes) descend from the myeloid lineage, and express blood DC antigen (BDCA)-1 (=CD1c), CD11c, and Toll-like receptors TLR2, TLR4, TLR5, and TLR3 [13-15]. They secrete mainly IL-12 in response to bacterial components such as peptidoglycans, lipopolysaccharide (LPS) or flagellin, and extracellular bacterial DNA, respectively. Unlike mDCs, pDCs $(0.2 \%$ among leukocytes) express BDCA-2 (= CD303) and CD123, and are specialized in innate antiviral immune responses by producing copious amounts of type I interferons upon exposure of intracellular TLR9 and TLR7 to DNA and RNA viruses, respectively [16-18]. Apart from responding to different pathogen-associated molecular patterns (PAMPs) and secreting different cytokines, $\mathrm{mDCs}$ and $\mathrm{pDCs}$ also differ in migration behaviour $[16,17,19-22]$. Generally it is assumed that $\mathrm{mDCs}$ are the conventional DCs that infiltrate peripheral tissues while pDCs migrate directly from the blood into lymphoid organs.

Finally, a small ( $0.02 \%$ of leukocytes) third population of blood DCs expressing CD11c, and BDCA-3 (= CD141) but not BDCA-1, CD123 and BDCA-2 can be distinguished [23]. BDCA $-3^{+}$mDCs are far less studied than the classical BDCA$1^{+} \mathrm{mDCs}$, but recent reports stress their unique function and importance. They emerge as a distinctive myeloid DC subset that is characterized by high expression of TLR3, production of IL-12 and IFN- $\beta$, and a superior capacity to induce $\mathrm{T}$ helper-1 cell responses, when compared with BDCA$1^{+}$mDCs [24]. Moreover, BDCA- $3^{+}$mDCs are endowed with the capacity to cross-present necrotic cell antigens and induce cytotoxic T-cell responses [24].

2.2. Decline of Blood DCs in CAD. In 2006 we reported for the first time a decrease in circulating DC precursors (BDCA$\left.1^{+} \mathrm{mDCs}, \mathrm{BDCA}-2^{+} \mathrm{pDCs}\right)$ in patients with coronary artery disease $(\mathrm{CAD})$, the clinical manifestation of atherosclerosis [25]. CAD was determined by angiography and defined as more than $50 \%$ stenosis in one or more coronary arteries. Blood DCs were enumerated by multicolour flow cytometry. Absolute and relative numbers of circulating BDCA-2 ${ }^{+}$ pDCs were significantly lower (55\% decline) in $18 \mathrm{CAD}$ patients, compared to 18 age- and sex-matched healthy volunteers. Absolute BDCA- $1^{+}$mDC numbers tended to be smaller in patients, while relative numbers were significantly diminished (21\% decline). Simultaneously and independently, Yilmaz et al. [26] also found a marked reduction in $\mathrm{mDC}$ precursors in CAD patients, though the decline in $\mathrm{pDCs}$ was less pronounced. These minor differences between both early reports may be due to insufficient power of those studies. In addition, Yilmaz et al. showed that patients with acute myocardial infarction (AMI), which were excluded by van Vré et al. [25], had the most dramatic decline $(63 \%)$ in blood mDCs [26]. However, this may be 
in response to development of myocardial necrosis rather than atherosclerosis in se. Moreover, it may be due to the doubling of the total leukocyte count after AMI, resulting in lower relative numbers of $\mathrm{mDCs}$ in patients with AMI, but comparable absolute counts between AMI patients and patients with stable CAD. This illustrates an important technical weakness of flow cytometric enumeration and stresses the importance of fairly stable unaltered total leukocyte counts, as flow cytometry determines the relative fraction of DCs within the total leukocyte population. Otherwise it would be preferable to add fluorescent beads as internal standards to the blood sample, which allows for absolute cell counting.

Subsequently, we investigated whether the decline of blood DCs in CAD patients was related to the number of diseased vessels (one- versus three-vessel disease) or type (stable versus unstable angina pectoris) of CAD [27]. This study also determined total blood DCs, identified as lineage (CD3, CD14, CD16, CD19, CD20, CD56) negative and HLADR positive. Again relative and absolute numbers of $\mathrm{pDCs}$ and $\mathrm{mDCs}$ were significantly lower (35 and 34\%, resp.) in patients with coronary atherosclerosis. Interestingly, the overall lineage ${ }^{-}$HLA-DR ${ }^{+}$blood DCs, which also include other blood DCs (e.g., BDCA- $3^{+}$) or more mature blood DCs, confirmed the decline of $\mathrm{BDCA}^{+}$DC precursors. However, the counts of circulating DCs dropped to the same extent in three groups of CAD patients, irrespective of the number (one or three) of affected arteries or the type (stable or unstable) of angina. In analogy, Yilmaz et al. found no differences between clinically stable or unstable CAD [26]. Yet, in a subsequent more extended study [28] with a cohort of 290 patients, they found that the numbers of pDCs, mDCs, and total DCs declined as the extent of coronary atherosclerosis increased. In that study they examined patients with suspected stable CAD, but used a more refined "CAD score." They assessed the maximum grade of stenosis in 15 well-defined segments of the three coronary arteries and their main side branches. These values were counted up to obtain an overall CAD score, and then patients were subdivided into 4 groups: CAD excluded, early CAD, moderate CAD, and advanced CAD. Moreover, they showed that the decrease in DC numbers was an independent predictor of the presence of CAD when several risk factors (age, male gender, diabetes, and hypertension) were included [28].

Surprisingly, Shi et al. [29] using CD11c and CD123 rather than BDCA-1 and BDCA-2 as blood DC markers, described increased $\mathrm{CD} 11 \mathrm{c}^{+}$and unchanged $\mathrm{CD} 123^{+} \mathrm{DC}$ numbers in men with stable CAD. Yet, recently we underlined that circulating DCs decline in CAD, irrespective of the subset marker (BDCA-1 or CD11c for mDCs, BDCA-2 or CD123 for pDCs) that was used for enumeration [30]. No details on timing of blood sampling are mentioned by Shi et al. It may be that in the CAD patients blood samples were taken immediately after a percutaneous coronary intervention (PCI). Since we noticed that PCI resulted in decreased leukocyte numbers shortly after the intervention (unpublished data, Van Vré et al.), this may have invoked a rise of the relative proportions of DC counts. Therefore, with respect to standardisation and to minimize interfering factors, blood sampling before the intervention seems preferable.

\subsection{Possible Explanations for the Decline of Blood DCs in CAD.} At the moment the mechanisms responsible for the decline of blood DCs in atherosclerosis are still unclear. Different possibilities are discussed below and summarized in Figure 2.

\subsubsection{Impaired Differentiation from Bone Marrow Progenitors.} Decreased production or release from the bone marrow could result in reduced blood DC precursor numbers. As discussed above, DCs are also necessary for induction of tolerance against harmless antigens $[5,31]$. Consequently, a diminution in DC precursors could promote the development of (auto)immune disease, such as atherosclerosis [32]. Interestingly, we recently showed diminished plasma Flt3 ligand (Flt3L) concentrations in CAD [12]. Flt3L is a major cytokine involved in both $\mathrm{pDC}$ and $\mathrm{mDC}$ development from haematopoietic stem cells and their release from the bone marrow [33-35]. As plasma Flt3L correlated with blood DC counts, the reduced blood DCs in CAD might be caused by impaired DC differentiation from bone marrow progenitors. Until now, it remains unclear why plasma Flt3L levels are lowered in CAD. In contrast, plasma concentrations of the DC growth factor GM-CSF were similar in CAD patients and controls and did not correlate with $\mathrm{mDC}$ or pDC counts [12], indicating that it is unlikely that GM-CSF accounts for the decreased numbers of blood DCs in human CAD.

2.3.2. Increased DC Turnover. Another explanation for the decreased DC numbers could be the result of increased turnover, that is, decreased survival or production versus apoptosis rates. Atherosclerosis is a chronic disease, evolving over several decades with inflammatory reactions taking place from the earlier stages. It is plausible that in the end as symptoms emerge and the exposure to (new) antigensderived from stressed and dying cells, lipid, or protein modifications due to oxidative stress in the plaque-increases, the immune system's "reserve pool" has become exhausted. For instance it was demonstrated that oxidized low-density lipoprotein, one of the main antigens present in plaques and in the circulation of atherosclerotic patients, may cause increased apoptosis of DCs [36]. Interestingly, no decline was observed [25-27] for other blood cells, such as monocytes, pointing to a specific role of DCs in atherogenesis. As DCs form the major patrol system of the body, involved in firstline defence, innate and adaptive immunity, they may be the most sensitive/vulnerable to local and systemic changes, or neoepitopes, presented during atherosclerosis. In the end, this may result in a system that is no longer able to sustain the number of blood DCs. Indeed, numbers of circulating blood DCs, in particular pDCs, decline with increasing age (unpublished data, Van Vré et al.). However, when age was included as covariate, the decline of $\mathrm{mDC}$ and $\mathrm{pDC}$ in $\mathrm{CAD}$ patients appeared to be independent of the effect of age [27].

2.3.3. DC Activation Leading to Loss of Subset Markers. Activation of blood DCs by factors in the circulation (e.g., 


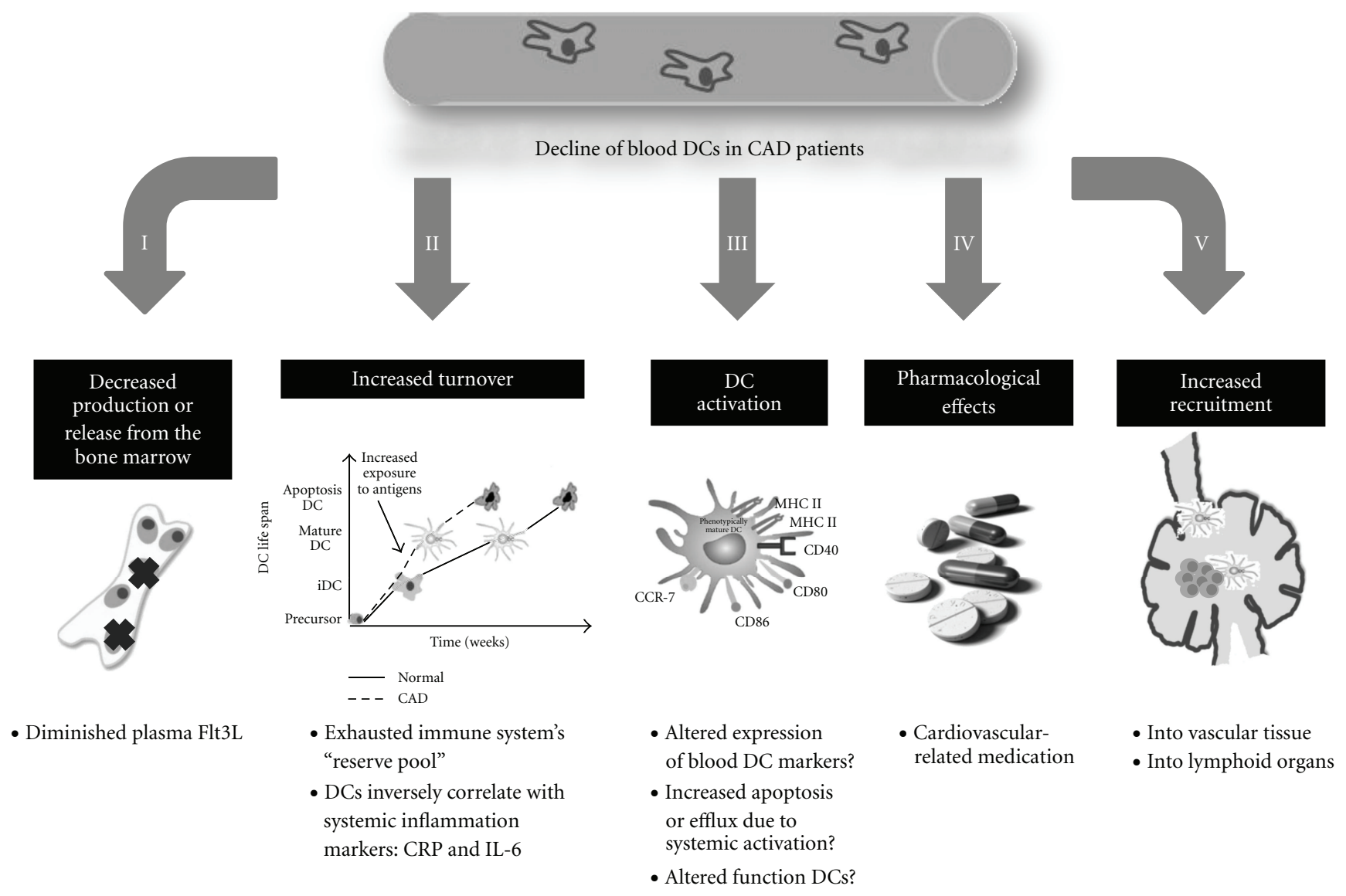

FIgURE 2: Possible mechanisms responsible for the decline of blood DCs in atherosclerosis.

oxLDL) could account for diminished blood DC numbers by reducing the expression of precursor markers. Indeed, it has been described that $\mathrm{pDC}$ maturation results in complete BDCA-2 downregulation $[23,30,37]$, and this could potentially lead to underestimation of circulating pDC numbers. In addition, we recently showed that ex vivo DC activation resulted in an increase in CD11c on mDCs and CD123 on pDCs [30]. Thus, when different DC numbers are found between study populations, the DC activation status needs to be verified, since the numerical changes may result from the altered expression of the subset markers during activation [30]. Yet, by using CD11c/BDCA-1 and CD123/BDCA-2 ratios to assess DC activation, no differences were found between controls and CAD patients [30]. From this it was concluded that there was no indication for overt activation of DC precursors in patients with CAD.

2.3.4. DC Activation Leading to Increased Extravasation. Though several studies investigated numbers of subsets of DCs in the circulation of CAD patients, very little additional information is available on the status of maturation and activation in circulating DCs. It is possible that in inflammatory conditions systemic activation occurs in the blood and this could lead to increased extravasation or apoptosis of blood
DCs. Interestingly, inverse associations of circulating mDCs, pDCs (and total DCs) were found with blood markers of inflammation: CRP and IL-6 [25-28]. Upon stimulation by circulating oxLDL or other atherosclerosis-related modified proteins, blood DCs may become activated, upregulate chemokine receptors such as CCR-7, and then travel towards lymphoid organs or inflamed tissues, such as atherosclerotic plaques.

Yilmaz et al. assessed the activation status of blood DC precursors and reported a weak expression of costimulatory molecules CD40 and CD86 on circulating BDCA- $1^{+}$mDCs or BDCA-2 ${ }^{+}$pDCs [26], without differences between control and CAD patients. We also detected very few activated blood DCs: a minority of circulating mDCs (14-22\%) and pDCs (14-20\%) had a more mature phenotype and expressed but low levels (MFI) of CD83, CD86, and/or CCR7. Nevertheless, we showed that the frequency of CD86 and CCR-7 expressing $\mathrm{mDC}$ was less in CAD patients whereas this was not seen in pDCs [12]. This could point to increased efflux or apoptosis of activated blood $\mathrm{CD} 86^{+} \mathrm{CCR}-7^{+} \mathrm{mDCs}$, contributing to their decline in blood.

2.3.5. Functional Capability of Circulating DC Precursors in $C A D$. As blood DC precursors from CAD patients remained 
fairly immature, we investigated their capability to achieve maturation. Therefore, we incubated whole blood samples with TLR ligands ex vivo, and then evaluated expression of activation markers by means of flow cytometry. Stimulation with the TLR-4 ligand LPS upregulated the expression of CD83 and CD86 on mDCs, without changing CCR-7 expression or IL-12 secretion. Moreover, there were no differences between mDCs from CAD patients or controls. For pDCs, patients showed a weaker upregulation of CD83 and less IFN-alpha secretion upon stimulation with imiquimod, a TLR7 ligand. Hence, these results indicate that although mDCs decline in CAD patients, they appear to be functioning in a normal way. In contrast, pDCs from CAD patients are not only reduced in numbers, but also seem subactive [12].

Finally, as monocytes can serve as precursors for DCs in peripheral tissues [38], three groups used a completely different approach and studied the function of monocytederived (mo)DCs in CAD. They isolated peripheral blood monocytes from CAD patients and differentiated them ex vivo for several days with GM-CSF and IL-4. moDCs from patients with coronary syndromes, particularly unstable angina, appeared to be more activated compared to moDCs from controls or healthy volunteers [39-41]. These data suggest that monocytes from CAD patients when exposed to DC growth factors in atherosclerotic lesions will be more prone to differentiate into activated DCs.

2.3.6. Drug-Induced Changes in Blood DCs. Cardiovascular disease-related medication, taken by CAD patients, might influence numbers, phenotype, or function of blood DCs in atherosclerosis. Indeed, several in vitro studies show potential effects of cardiovascular drugs on DC maturation and function.

Aspirin promotes early moDC differentiation to functionally active, immature DCs, and strongly maintains these cells in an immature state [42-44]. In vivo experiments in mice demonstrated an impairment of cell-mediated immune responses, which was not due to the inability of aspirintreated DCs to migrate to drained lymphoid tissue [42]. In contrast to immature DCs, fully differentiated DCs were not susceptible to inhibition by aspirin [43]. The latter indicates that it is the process of differentiation, rather than the function of mature DCs, which is the target of aspirin.

Kofler et al. demonstrated that statins inhibited adhesion and transmigration of moDCs through dysfunctional endothelial cells in vitro [45], suggesting that under statin treatment less DCs would accumulate in atherosclerotic plaques. Although statins have been reported to suppress DC maturation and function, [46-48], data on in vitro DC activation in the presence of statins remain rather conflicting. It seems that statins partially suppress in vitro DC maturation by inhibition of the $\mathrm{NF} \mathcal{K} \mathrm{B}$ activity [48], but may affect DC function differently [46] depending on the maturation parameters analysed and the type of statin tested.

Studies on the effects of beta blockers on DC maturation and function are absent, though beta blockers may reverse changes in leukocyte distribution. Von Haehling et al. demonstrated that the decrease in lymphocytes and the in-crease in neutrophils in patients with chronic heart failure are less pronounced when patients are on a betablocker therapy [49]. After distal type acute aortic dissection, early use of beta blockers prevented excessive inflammation, indicated by lower maximum white blood cell counts and lower serum CRP levels. This suggests pleiotropic effects of beta blockers on the inflammatory response [50].

Also angiotensin-converting enzyme- (ACE-) inhibitors and calcium entry blockers, two groups of pharmaceuticals that are used primarily in treatment of hypertension, might influence DC function. ACE-inhibitors were shown to suppress LPS-induced proinflammatory cytokine secretion of moDCs [51] whereas calcium entry blockers prevent apoptotic body engulfment by DCs and inhibit IL-12 secretion $[52,53]$. Yet, calcium entry blockers did not affect the capacity of antigen-presenting cells to prime naive $\mathrm{T}$ cells or to induce T helper- 2 cell proliferation, nor the capacity of antigen-presentation by DCs [54]. Hence, both classes of antihypertensive drugs may suppress DC function, but are less commonly used in the treatment of CAD patients.

If these in vitro studies on the effects of cardiovascular drugs on human moDCs and mouse bone-marrow-derived DCs can be translated to CAD patients, they would affect blood DC numbers. As aspirin stimulates early differentiation of CD11 $\mathrm{c}^{+} \mathrm{DCs}$ from bone marrow progenitors, aspirin therapy might lead to increased circulating DC numbers rather than decreased numbers. Furthermore, if statins inhibit the adhesion and transmigration of DCs through activated endothelial cells, this would result in less recruitment of DCs in atherosclerotic plaques, and thus retention of DCs in the circulation. Indeed, we showed recently that use of statins was associated with increased numbers of mDCs whereas pDC counts were unaffected [27]. Also DC activation is to some extent inhibited by statins, aspirin, ACE-I, and calcium entry blockers, which might explain their immature phenotype in an inflammatory condition as atherosclerosis. Finally, as beta blockers might reverse changes in leukocyte distribution and have pleiotropic effects on inflammatory responses, the decline of circulating DCs in CAD may be less pronounced in patients on a beta-blocker therapy as well.

In a recent study, we analyzed the effect of medication by including "control patients," that is, patients with chest pain and suspected CAD, who appeared to have coronary arteries with less than $50 \%$ stenosis, instead of healthy volunteers [27]. This control population did not significantly differ from CAD patients with respect to the intake of medication. Yet, patients with proven CAD had lower blood counts of both subsets of DCs, strengthening the idea that their decline in CAD is not a bystander effect of cardiovascularrelated drugs. Yilmaz et al. came to the same conclusion for statins, aspirin and beta blockers [28]. Moreover, in a factorial analysis of variance lipid-lowering drugs and beta blockers augmented, rather than decreased, the number of circulating mDCs in $\mathrm{CAD}$, without affecting pDCs. Aspirin, angiotensin-converting enzyme ACE/AII inhibitors and calcium entry blockers had no impact on DC numbers [27]. As this was only a limited pilot study, more studies are 
required to investigate the impact of medication on circulating DC numbers and function.

2.3.7. Increased Recruitment of DCs from the Circulation to Inflammatory Sites. An attractive explanation for decreased circulating DC numbers might be increased recruitment of DCs into the vessel wall or lymphoid organs. Indeed it has been mentioned that DC numbers of lymph nodes attached to atherosclerotic wall segments exceed those in lymph nodes attached to nonatherosclerotic arteries [7]. As to the presence of DCs in healthy and diseased arteries, several studies have been done and these are discussed in the second part of this review.

\section{DCs in Atherosclerotic Lesions}

The presence of DCs in human arteries was first described by Bobryshev and Lord 1995 [55-57]. By electron microscopy they demonstrated distinct morphologic characteristics that allow unambiguous identification of "vascular DCs" [7, $55,58,59]$. In addition, DCs in human arteries were identified using immunohistochemical staining for S100 (Figure 3(a)) [56], langerin [60], CD1a [61], and fascin (Figure 3(b)) [62], which identify immature/mature subsets of DCs. More recent histological studies added a general (immature and mature) DC marker: DC-SIGN $[63,64]$ and mature DC markers, such as DC-LAMP [65], CDla [58, 60], and CD83 [65-67]. Therefore, as suggested above, an attractive explanation for the decline in blood DCs is active recruitment into atherosclerotic lesions. Indeed, the presence of blood DC markers BDCA-1, BDCA-2 [26, 68, 69], CD11c, and $\mathrm{CD} 123$ [70-73] has been described in atherosclerotic plaques. Nevertheless, as summarized in Table 1 and discussed below, there remains a lot of uncertainty on quality and specificity of immunohistochemical DC markers.

3.1. Pitfalls When Examining DCs in Atherosclerotic Plaques. At first, it became clear that autolysis in autopsy specimens and fixation destroy or shield most cell surface (CD) epitopes [69]. This means that nearly all DC markers cannot be studied in formaldehyde-fixed human autopsy specimens, and therefore information on their presence in early plaque stages is lacking. For these surface markers (e.g., CD83, and BDCA-1, BDCA-2) only freshly frozen, unfixed endarterectomy specimens yield reliable results [69].

Secondly, false-positive results, resulting from unspecific binding of antibodies to plaque components often occur in atherosclerotic plaques [82]. The oxidative processes in advanced plaques lead to creation of hot spots of multiple neoantigens, and these may bind primary or secondary antibodies, particularly if used in inappropriate dilutions. Therefore, optimized immunohistochemistry protocols are an absolute prerequisite. For instance $\operatorname{CD} 83[63,67,69]$ and BDCA antigens [69] could be detected in human plaques [69], but they were less eminently present than reported by others $[26,65,83]$. Actually we suspect that in some studies the primary antibody against those epitopes was far too concentrated, and even combined with signal amplification methods that will increase background staining even further.

Thirdly the lack of DC specific markers makes identification of vascular DCs by means of immunohistochemistry far more difficult than with flow cytometry in which a panel of markers enables unequivocal positive or negative (for other lineages) detection of various cell types. For instance, the markers CD11c and CD123, which have been used to detect blood DCs in plaques [70, 84], are also expressed by, respectively, monocytes/macrophages and endothelial cells [69]. Fascin is most frequently used to detect vascular DCs $[62,65,66,68,73-76]$, but we recently showed abundant fascin expression in endothelial cells and neovessels in plaque shoulders and in complicated lesions [69, 77] (Figure 3(c)). Also the lipid antigen presenting molecule, CDla appeared to be unspecific for plaque DCs as it identified also foam cells, CD $14^{+}$monocytes, and $\mathrm{CD}^{+} 8^{+}$macrophages $[69,81]$, whereas the activation marker CD83 can be present on Tcells or activated monocytes and macrophages in advanced plaques $[69,85,86]$. Though double immunofluorescence staining can be used to check multiple markers on individual cells, the very high levels of autofluorescence in atherosclerotic plaques make routine application of this technique impossible. At the moment we propose S100 as the most reliable and general marker of DCs in plaques DCs (Figure 3(a)), but not in the adventitia where it stains nerve twigs. Fascin may yield reliable results (Figure 3(b)), but only in early lesions that are still devoid of intraplaque angiogenesis.

Finally, there is no universal DC marker that is expressed by all DCs. Indeed, few DCs simultaneously expressed the most reliable markers fascin and S100 [69], and the presence of DCs as detected by immunohistochemistry is markedly lower than DC numbers identified by electronmicroscopy $[55,58]$. Therefore, one has to keep in mind that quantification of intimal DCs by one marker will only give information on a particular DC subtype.

\subsection{Different DC Subtypes in Atherosclerotic Lesions}

3.2.1. DC Precursors in Advanced Atherosclerotic Plaques. Interestingly, both $\mathrm{mDC}$ and $\mathrm{pDC}$ precursor markers were found in carotid atherosclerotic plaques, although less BDCA- $2^{+}$(pDC marker) cells were present [69]. Yilmaz et al. described comparable results in atherosclerotic coronary arteries [26]. These findings are substantiated by the fact that gene expression analysis for pathogen-sensing Toll-like receptors (TLRs) 1 to 9 showed vessel-specific profiles, with the mDC receptors TLR2 and TLR4 ubiquitously present, but the pDC receptors TLR7 and TLR9 infrequently so [87]. Niessner et al. described the presence of plaque residing $\mathrm{CD} 23^{+} \mathrm{pDCs}$ in advanced plaques, suggesting that they can amplify cytolytic T-cell functions and may thus connect host infection and plaque instability [70].

The demonstration of BDCA- $2^{+}$and $\mathrm{BDCA}-1^{+}$cells in human plaques strongly suggests that blood DCs are recruit-ed into advanced lesions. This is further strengthened by the observation that both $\mathrm{BDCA}^{+}$subsets were 
TABLE 1: Immunohistochemical markers to identify DCs in human plaques.

\begin{tabular}{|c|c|c|c|c|}
\hline Marker & DC type & References & Pitfalls & References \\
\hline Fascin $(\mathrm{p} 55)$ & $\begin{array}{l}\text { Immature/mature DCs; DC } \\
\text { specific in early plaque stages }\end{array}$ & $\begin{array}{l}{[7,59,62} \\
65,66,68 \\
69,73-77]\end{array}$ & $\begin{array}{l}\text { Capillary ECs, migrating } \\
\text { vascular cells in plaque shoulders } \\
\text { and advanced plaques }\end{array}$ & {$[69,77]$} \\
\hline S100 (S100B and weakly S100A1) & $\begin{array}{l}\text { Immature/mature DCs; DC } \\
\text { specific in normal intima and all } \\
\text { plaque stages }\end{array}$ & $\begin{array}{l}{[7,7,56} \\
59,61,65 \\
68,69,77- \\
79]\end{array}$ & $\begin{array}{l}\text { Nerve bundles and twigs in } \\
\text { adventitia }\end{array}$ & {$[7,56,59,69]$} \\
\hline Langerin & $\begin{array}{l}\text { Selectively expressed on the } \\
\text { surface and in Birbeck granules } \\
\text { of Langerhans cells }\end{array}$ & {$[60,69]$} & Very few cells & {$[60,69]$} \\
\hline CD1a & Mature DCs & $\begin{array}{l}{[67,74,78,} \\
80]\end{array}$ & $\mathrm{CD}_{14}{ }^{+}, \mathrm{CD} 8^{+}$foam cells & {$[69,81]$} \\
\hline CD83 & Mature DCs & {$[65-67]$} & $\begin{array}{l}\text { Aspecific staining due to signal } \\
\text { amplification? Activated T cells } \\
\text { and monocytes? }\end{array}$ & {$[63,69]$} \\
\hline DC-SIGN (CD209) & Immature/mature DCs & {$[63,64]$} & Macrophages & {$[63]$} \\
\hline DC-LAMP (CD208) & Mature DCs & {$[65]$} & & \\
\hline BDCA-1 (CD1c) & $\mathrm{mDC}$ & $\begin{array}{l}{[26,68,} \\
69]\end{array}$ & B cells & {$[23]$} \\
\hline BDCA-2 (CD303) & pDC precursor & $\begin{array}{l}{[26,68,} \\
69]\end{array}$ & & {$[23,38]$} \\
\hline $\mathrm{CD} 11 \mathrm{c}$ & $\mathrm{mDCs}$ & {$[71-73]$} & $\begin{array}{l}\mathrm{CD} 14^{+} \text {monocytes and } \mathrm{CD} 68^{+} \\
\text {macrophages }\end{array}$ & {$[69]$} \\
\hline CD123 & pDCs & {$[70-73]$} & $\begin{array}{l}\text { ECs, microvessels in advanced } \\
\text { plaques, and plaque shoulders }\end{array}$ & {$[69]$} \\
\hline
\end{tabular}

DC: dendritic cells, EC: endothelial cell, pDC: plasmacytoid DC, mDC: myeloid DC.

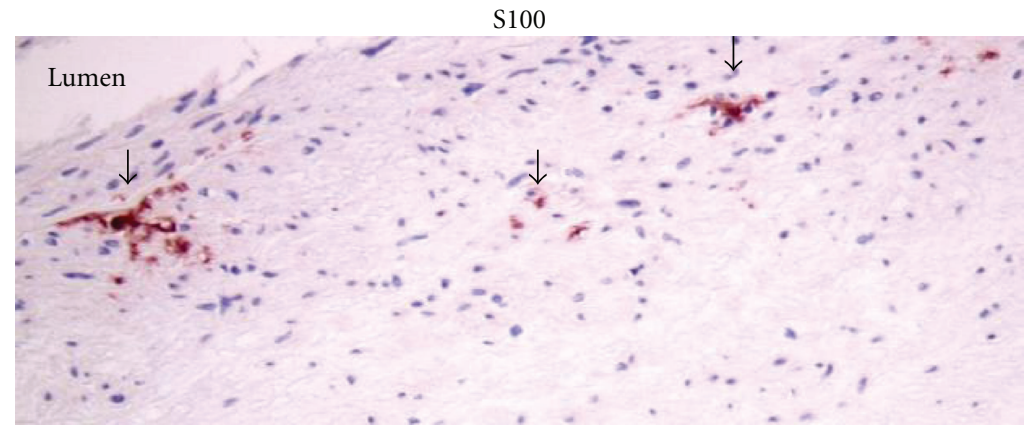

(a)

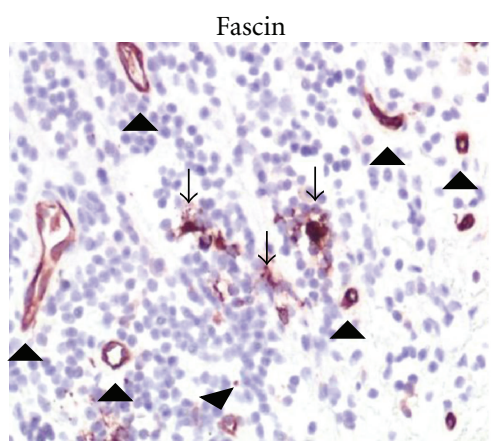

(c)

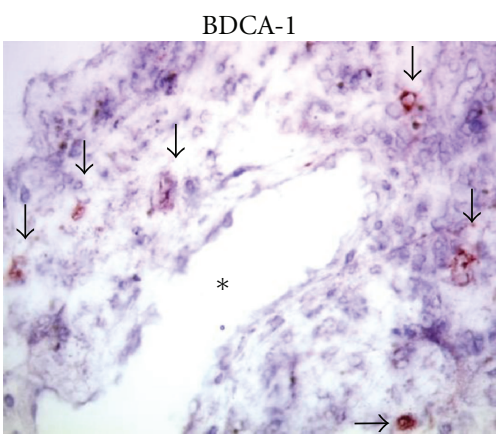

(d)

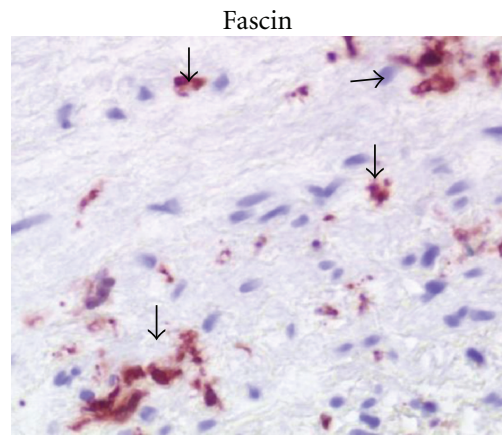

(b)

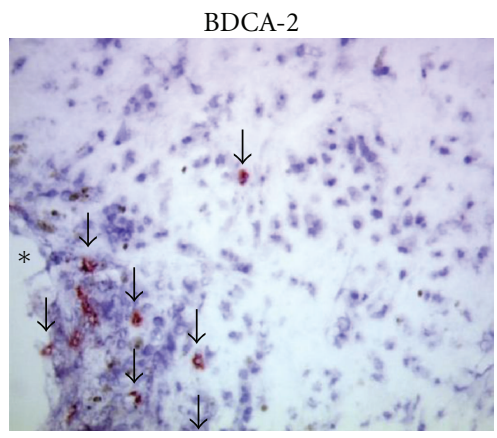

(e)

Figure 3: Examples of useful plaque DC markers: S100 (a), fascin (b, c), BDCA-1 (d) and BDCA-2 (e). Arrows indicate DCs. Arrowheads show fascin ${ }^{+}$neovessels. $*$ indicates lumen of microvessel. 


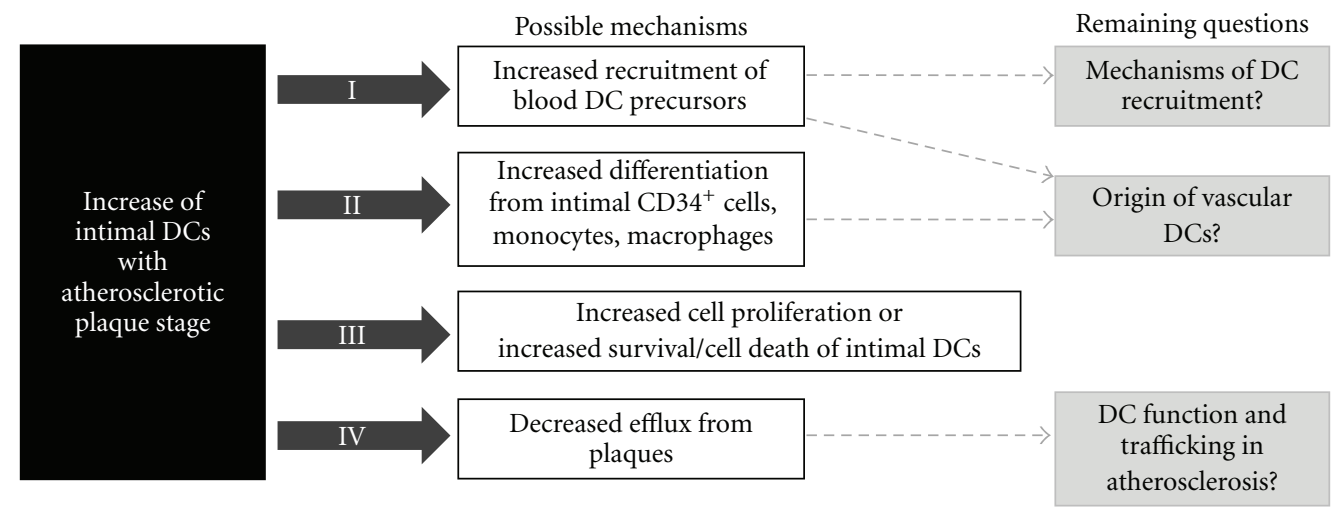

FIgURE 4: Possible mechanisms responsible for the increase of vascular DCs in atherosclerosis.

predominantly found around microvessels [69]. At the moment there still is a lack of information on their potential presence in early atherosclerotic lesions, due to the fact that their markers cannot be investigated in fixed arteries.

3.2.2. Immature/Mature DCs in Atherosclerotic Plaques. $\mathrm{S} 100^{+}$and fascin $^{+}$DCs are found in normal arteries and in all successive stages of atherosclerotic lesions [7, 59, 65, 69]. Interestingly, atheroprone regions (subjected to hemodynamic stress) contain more DCs than atheroresistant areas [88]. Small numbers of DCs are located along the endothelium in the subendothelial layer of the intima of apparently normal, nondiseased arteries, even in children $[78,89]$. Wick et al. proposed that these intimal DCs are part of a "vascular associated lymphoid tissue" (VALT), which also consists of T cells and macrophages, and screens the vessel wall for potentially harmful antigens $[32,90,91]$.

Though the presence of S100 in normal intimal thickenings is limited, numbers of $\mathrm{S} 00^{+}$cells increase successively from intimal thickening, via pathological intimal thickening, fibrous cap atheroma and finally complicated plaques [56, 69]. Fascin ${ }^{+}$cells follow the same pattern, but are more abundant $[26,69,76,83]$. For early plaque stages this is a real find zing, but in lesions containing microvessels (plaque shoulders, complicated plaques, and most endarterectomy specimens) this was partly ex-plained by staining of fascinpositive endothelial cells [69].

3.2.3. Mature, Antigen-Presenting DCs in Atherogenic Lesions. The report on abundant presence of $\mathrm{CD} 83^{+}$cells in plaque shoulders [65] is often cited as evidence that atherosclerotic plaques contain many activated DCs. However the markers CD1a and CD83 are technically difficult or less specific for detection of mature DCs. Therefore, it is in our view still debatable whether mature DC counts augment when plaque stages increase. Nevertheless, mature DCs can be found in advanced lesions, and it became clear that DCs form close interactions with $\mathrm{T}$ cells in advanced atherosclerotic lesions, suggesting that in situ T-cell activation does occur $[65,67,69$, 74].
3.3. Possible Mechanisms for Increased DCs in Atherosclerotic Arteries. Different explanations for increased DC numbers in atherosclerotic lesions are discussed below and summarized in Figure 4.

3.3.1. Increased Influx of Blood DC Precursors. At first and in view of the many reports on diminished blood DCs in patients with established atherosclerosis, one likely explanation is increased invasion of DC precursors from the blood into the arterial lesions. This hypothesis is strengthened by the present markers of pDCs and mDCs around neovessels. Future studies will have to determine whether a link exists not only between plaque type and numbers of lesional DCs, but also with blood DC counts. It is possible that, the clinical division in stable or unstable, was not refined enough to detect this correlation. Ideally, DCs have to be investigated in peripheral blood and plaque samples of the same patient, or in an animal model of experimental atherosclerosis, with fluorescence labeling of DCs, to characterize their origin, to postulate an increased influx of blood DC precursors as a mechanism for increased DC numbers in atherosclerotic plaques. Direct information on the stimuli regulating DC migration is scarce. However, it is known that effective mDC as well as pDC chemokine factors (CCL2, CCL5, and CXCL-12) are elevated in patients with atherosclerosis [2022, 92]. In addition, endothelial cell adhesion molecules such as E-selectin, P-selectin, and vascular cell adhesion molecule- 1 are increased in atherosclerosis and can enhance invasion of monocytes or DC precursors [68]. Indeed, endothelium activated in vitro by atherogenic factors such as oxLDL or TNFalpha increases moDC adhesion and endothelial transmigration [93]. Furthermore, we recently showed that endothelial cell dysfunction in humans (measured by brachial vasodilatation in response to reactive hyperaemia) does have an impact on the number of circulating mDCs. Poor vasodilatation increased mDCs (but not pDCs) in the blood, on top of the reduction evoked by CAD [27]. Finally, experimental studies in mice suggest that DCs invade the plaque via the arterial lumen [94] while the proliferation rate of DCs in plaques is very low [95]. Interestingly, deficiency in CX3CR1 - a receptor of the chemokine fractalkine-in mice 
impaired the accumulation of DCs in the aortic wall and this markedly reduced the atherosclerotic burden [96].

3.3.2. Increased Differentiation from Intimal $\mathrm{CD} 34^{+}$Cells or Monocytes. In spite of these indications that blood DC precursors might account for increased plaque DC numbers, the origin of immature/mature $\left(\mathrm{S}_{100^{+}}\right.$or fascin $\left.{ }^{+}\right)$DCs remains unclear [7]. Until now it has not been shown that DC precursors can give rise to plaque DCs [38]. Therefore, a second and third explanation for the augmented presence of DCs in atherosclerotic plaques are increased differentiation of DCs from local vascular CD34 ${ }^{+}$stem cells [59] or from infiltrated monocytes $[38,59,95,97]$. Interestingly, aortic lesions of GM-CSF-deficient low-density lipoprotein receptor null mice had a dramatic $60 \%$ decrease in $\mathrm{CD}_{11 \mathrm{c}^{+}}$ DCs, suggesting that GM-CSF might be an important local factor that determines DC numbers in the plaques [98]. In addition, several studies already pointed to the fact that atherogenic factors such as oxLDL, phospholipase A2 type IIA, and CRP could interfere with DC differentiation from monocytes [99-101]. Moreover, next to monocytes also macrophages and foam cells can turn into DCs $[99,102]$. As discussed below, this transition might be necessary to enable migration to lymph nodes and plaque regression $[103,104]$.

\subsubsection{Defective Emigration of DCs from Plaque to Lymphoid} Organs. It was recently suggested that the accumulation of DCs in plaques could be the result of defective emigration of DCs from the lesions to draining lymph nodes [38, 105]. In a mouse model of dyslipidemia it was shown that altered serum lipids associated with atherosclerosis changed DC activation and migration [106]. Further evidence was given by transplantation of atherosclerotic segments from hypercholesterolemic $\mathrm{ApoE}^{-/-}$mice into wildtype normocholesterolemic recipient mice. This resulted in lesion regression whereas lesion development continued progressively after transplantation into hypercholesterolemic mice $[104,107,108]$. The rapid loss of plaque volume after transplantation of segments into normocholesterolemic mice, was explained by emigration of DCs to lymph nodes $[104,109]$, while DC exit from aortic lesions was impaired in hypercholesterolemic mice [104]. Trogan et al. demonstrated that CCR7 was increased after transplantation of the plaques in normolipidemic mice [103]. In contrast, when CCR7 function was abrogated in vivo by treatment with antibodies to CCR7 ligands CCL19 and CCL21, lesion size and foam cell content did not regress [103]. Doherty et al. explained that - in accordance with giant cell arteritis [110] — trapped intimal DCs may not only trigger local inflammation, but it may also lead to loss of local tolerance [105]. Nevertheless, in human atherosclerotic arteries DCs can be regularly observed trafficking through the media and the internal elastic lamina $[69,74]$, but it is not known whether the rate of cell fluxes has changed.

\section{General Conclusion}

This review summarizes the current understanding of the possible role of DCs in the pathogenesis of human atherosclerosis. Concerning the early stages of DC differentiation, that is, circulating DC precursors, it is now unambiguous that they are significantly decreased in CAD patients, irres-pective of the blood DC markers used for enumeration. Exact mechanisms responsible for their decline remain unclear. However, there are indications pointing to impaired differentiation from bone marrow progenitors, and to activation and subsequent recruitment to inflammatory sites, such as atherosclerotic plaques. Indeed, both mDCs and pDCs can be found in human plaques, particularly around neovessels in areas with angiogenesis. Furthermore, DC counts in the intima of arteries increase with evolving plaque stages, and activated DCs are seen in close relationship with lesional $\mathrm{T}$ cells. To which extent these interactions between $\mathrm{DCs}$ and $\mathrm{T}$ cells result in progression or dampening of atherosclerosis is, however, not yet clear. Interestingly, it has been demonstrated in mice that decreased accumulation of DCs in the arterial intima can lead to attenuated plaque progression [96]. However, a protective role for DCs in atherosclerosis by regulating cholesterol homeostasis [111] has also been shown. Furthermore, increasing evidence points to different behaviour of mDCs and pDCs in atherosclerosis. The mDCs from CAD patients and controls responded similar to ex vivo stimulation, while pDCs from CAD patients were subactive. To elucidate possible atheropromoting or protective functions of blood DCs in humans, studies investigating the relationships between plaque composition, size, and stability by means of IVUS, and numbers and functional status of circulating pDCs and mDCs would be helpful. However, in the end experimental studies in animal models of atherosclerosis are required to unravel DC function, life cycle, activation, and trafficking in atherosclerosis. As DCs recognize atherosclerosis-related antigens and are renowned as potent immune-regulatory cells, they may possibly be manipulated and deployed in the future in order to delay the atherosclerotic disease process in humans.

\section{Authors' Contribution}

E. A. Van Vré and I. V. Brussel contributed equally to the paper.

\section{References}

[1] U. Singh and J. Ishwarlal, "Oxidative stress and atherosclerosis," Pathophysiology, vol. 13, no. 3, pp. 129-142, 2006.

[2] G. K. Hansson, A. K. Robertson, and C. SöderbergNauclér, "Inflammation and atherosclerosis," Annual Review of Pathology, vol. 1, pp. 297-329, 2006.

[3] D. R. Greaves and K. M. Channon, "Inflammation and immune responses in atherosclerosis," Trends in Immunology, vol. 23, no. 11, pp. 535-541, 2002.

[4] R. M. Steinman, D. Hawiger, and M. C. Nussenzweig, "Tolerogenic dendritic cells," Annual Review of Immunology, vol. 21, pp. 685-711, 2003.

[5] J. Banchereau, F. Briere, C. Caux et al., "Immunobiology of dendritic cells," Annual Review of Immunology, vol. 18, pp. 767-811, 2000. 
[6] Z. Mallat, H. Ait-Oufella, and A. Tedgui, "Regulatory TCell immunity in atherosclerosis," Trends in Cardiovascular Medicine, vol. 17, no. 4, pp. 113-118, 2007.

[7] Y. V. Bobryshev, "Dendritic cells in atherosclerosis: current status of the problem and clinical relevance," European Heart Journal, vol. 26, no. 17, pp. 1700-1704, 2005.

[8] M. Rossi and J. W. Young, "Human dendritic cells: potent antigen-presenting cells at the crossroads of innate and adaptive immunity," Journal of Immunology, vol. 175, no. 3, pp. 1373-1381, 2005.

[9] D. N. Hart, "Dendritic cells: unique leukocyte populations which control the primary immune response," Blood, vol. 90, no. 9, pp. 3245-3287, 1997.

[10] R. Thomas and P. E. Lipsky, "Human peripheral blood dendritic cell subsets: isolation and characterization of precursor and mature antigen-presenting cells," Journal of Immunology, vol. 153, no. 9, pp. 4016-4028, 1994.

[11] U. O’Doherty, M. Peng, S. Gezelter et al., "Human blood contains two subsets of dendritic cells, one immunologically mature and the other immature," Immunology, vol. 82, no. 3, pp. 487-493, 1994.

[12] I. van Brussel et al., "Decreased numbers of peripheral blood dendritic cells in patients with coronary artery disease are associated with diminished plasma Flt3 ligand levels and impaired plasmacytoid dendritic cell function," Clinical Science, vol. 120, no. 9, pp. 415-426, 2011.

[13] K. Shortman and Y. J. Liu, "Mouse and human dendritic cell subtypes," Nature Reviews Immunology, vol. 2, no. 3, pp. 151$161,2002$.

[14] D. Jarrossay, G. Napolitani, M. Colonna, F. Sallusto, and A. Lanzavecchia, "Specialization and complementarity in microbial molecule recognition by human myeloid and plasmacytoid dendritic cells," European Journal of Immunology, vol. 31, no. 11, pp. 3388-3393, 2001.

[15] N. Kadowaki, S. Ho, S. Antonenko et al., "Subsets of human dendritic cell precursors express different toll-like receptors and respond to different microbial antigens," Journal of Experimental Medicine, vol. 194, no. 6, pp. 863-869, 2001.

[16] W. Barchet, M. Cella, and M. Colonna, "Plasmacytoid dendritic cells_-virus experts of innate immunity," Seminars in Immunology, vol. 17, no. 4, pp. 253-261, 2005.

[17] M. Colonna, G. Trinchieri, and Y. J. Liu, "Plasmacytoid dendritic cells in immunity," Nature Immunology, vol. 5, no. 12, pp. 1219-1226, 2004.

[18] A. Dzionek, Y. Inagaki, K. Okawa et al., "Plasmacytoid dendritic cells: from specific surface markers to specific cellular functions," Human Immunology, vol. 63, no. 12, pp. 11331148, 2002.

[19] L. Wu and Y. J. Liu, "Development of dendritic-cell lineages," Immunity, vol. 26, no. 6, pp. 741-750, 2007.

[20] M. D. Gunn, "Chemokine mediated control of dendritic cell migration and function," Seminars in Immunology, vol. 15, no. 5, pp. 271-276, 2003.

[21] G. de La Rosa et al., "Migration of human blood dendritic cells across endothelial cell monolayers: adhesion molecules and chemokines involved in subset-specific transmigration," Journal of Leukocyte Biology, vol. 73, no. 5, pp. 639-649, 2003.

[22] G. Penna, M. Vulcano, S. Sozzani, and L. Adorini, "Differential migration behavior and chemokine production by myeloid and plasmacytoid dendritic cells," Human Immunology, vol. 63, no. 12, pp. 1164-1171, 2002.

[23] A. Dzionek, A. Fuchs, P. Schmidt et al., "BDCA-2, BDCA-3, and BDCA-4: three markers for distinct subsets of dendritic cells in human peripheral blood," Journal of Immunology, vol. 165, no. 11, pp. 6037-6046, 2000.

[24] S. L. Jongbloed, A. J. Kassianos, K. J. McDonald et al., "Human $\mathrm{CD} 141^{+}(\mathrm{BDCA}-3)^{+}$dendritic cells (DCs) represent a unique myeloid DC subset that cross-presents necrotic cell antigens," Journal of Experimental Medicine, vol. 207, no. 6, pp. 1247-1260, 2010.

[25] E. A. van Vré, V. Y. Hoymans, H. Bult et al., "Decreased number of circulating plasmacytoid dendritic cells in patients with atherosclerotic coronary artery disease," Coronary Artery Disease, vol. 17, no. 3, pp. 243-248, 2006.

[26] A. Yilmaz, J. Weber, I. Cicha et al., "Decrease in circulating myeloid dendritic cell precursors in coronary artery disease," Journal of the American College of Cardiology, vol. 48, no. 1, pp. 70-80, 2006.

[27] E. A. van Vré, I. van Brussel, K. O. de Beeck et al., "Changes in blood dendritic cell counts in relation to type of coronary artery disease and brachial endothelial cell function," Coronary Artery Disease, vol. 21, no. 2, pp. 87-96, 2010.

[28] A. Yilmaz, T. Schaller, I. Cicha et al., "Predictive value of the decrease in circulating dendritic cell precursors in stable coronary artery disease," Clinical Science, vol. 116, no. 4, pp. 353-363, 2009.

[29] H. Shi, J. Ge, W. Fang et al., "Peripheral-blood dendritic cells in men with coronary heart disease," American Journal of Cardiology, vol. 100, no. 4, pp. 593-597, 2007.

[30] I. van Brussel, E. A. van Vré, G. R. Y. de Meyer, C. J. Vrints, J. M. Bosmans, and H. Bult, "Expression of dendritic cell markers CD11c/BDCA-1 and CD123/BDCA-2 in coronary artery disease upon activation in whole blood," Journal of Immunological Methods, vol. 362, no. 1-2, pp. 168-175, 2010.

[31] J. Banchereau and R. M. Steinman, "Dendritic cells and the control of immunity," Nature, vol. 392, no. 6673, pp. 245252, 1998.

[32] G. Wick, M. Romen, A. Amberger et al., "Atherosclerosis, autoimmunity, and vascular-associated lymphoid tissue," FASEB Journal, vol. 11, no. 13, pp. 1199-1207, 1997.

[33] B. Blom, S. Ho, S. Antonenko, and Y. J. Liu, "Generation of interferon $\alpha$-producing predendritic cell (pre-DC) 2 from human CD $34^{+}$hematopoietic stem cells," Journal of Experimental Medicine, vol. 192, no. 12, pp. 1785-1795, 2000.

[34] W. Chen, S. Antonenko, J. M. Sederstrom et al., "Thrombopoietin cooperates with FLT3-ligand in the generation of plasmacytoid dendritic cell precursors from human hematopoietic progenitors," Blood, vol. 103, no. 7, pp. 2547-2553, 2004.

[35] M. Colonna, G. Trinchieri, and Y. J. Liu, "Plasmacytoid dendritic cells in immunity," Nature Immunology, vol. 5, no. 12, pp. 1219-1226, 2004.

[36] C. J. Alderman, P. R. Bunyard, B. M. Chain, J. C. Foreman, D. S. Leake, and D. R. Katz, "Effects of oxidised low density lipoprotein on dendritic cells: a possible immunoregulatory component of the atherogenic micro-environment?" Cardiovascular Research, vol. 55, no. 4, pp. 806-819, 2002.

[37] P. Wu, J. Wu, S. Liu et al., "TLR9/TLR7-triggered downregulation of BDCA2 expression on human plasmacytoid dendritic cells from healthy individuals and lupus patients," Clinical Immunology, vol. 129, no. 1, pp. 40-48, 2008.

[38] G. J. Randolph, J. Ochando, and S. Partida-Sánchez, "Migration of dendritic cell subsets and their precursors," Annual Review of Immunology, vol. 26, pp. 293-316, 2008.

[39] S. Ranjit, L. Dazhu, Z. Qiutang et al., "Differentiation of dendritic cells in monocyte cultures isolated from patients with unstable angina," International Journal of Cardiology, vol. 97, no. 3, pp. 551-555, 2004. 
[40] J. F. Dopheide, U. Sester, A. Schlitt et al., "Monocyte-derived dendritic cells of patients with coronary artery disease show an increased expression of costimulatory molecules CD40, CD80 and CD86 in vitro," Coronary Artery Disease, vol. 18, no. 7, pp. 523-531, 2007.

[41] L. Wang, D. Li, K. Yang, Y. Hu, and Q. Zeng, “Toll-like receptor-4 and mitogen-activated protein kinase signal system are involved in activation of dendritic cells in patients with acute coronary syndrome," Immunology, vol. 125, no. 1, pp. 122130, 2008.

[42] H. Hackstein, A. E. Morelli, A. T. Larregina et al., "Aspirin inhibits in vitro maturation and in vivo immunostimulatory function of murine myeloid dendritic cells," Journal of Immunology, vol. 166, no. 12, pp. 7053-7062, 2001.

[43] R. Matasic, A. B. Dietz, and S. Vuk-Pavlovic, "Cyclooxygenase-independent inhibition of dendritic cell maturation by aspirin," Immunology, vol. 101, no. 1, pp. 53-60, 2000.

[44] H. J. Kim, Y. H. Lee, S. A. Im, K. Kim, and C. K. Lee, "Cyclooxygenase inhibitors, aspirin and ibuprofen, inhibit MHCrestricted antigen presentation in dendritic cells," Immune Network, vol. 10, no. 3, pp. 92-98, 2010.

[45] S. Kofler, C. Schlichting, S. Jankl, T. Nickel, and M. Weis, "Dual mode of HMG-CoA reductase inhibition on dendritic cell invasion," Atherosclerosis, vol. 197, no. 1, pp. 105-110, 2008.

[46] A. Yilmaz, C. Reiss, A. Weng et al., "Differential effects of statins on relevant functions of human monocyte-derived dendritic cells," Journal of Leukocyte Biology, vol. 79, no. 3, pp. 529-538, 2006.

[47] A. Yilmaz, C. Reiss, O. Tantawi et al., "HMG-CoA reductase inhibitors suppress maturation of human dendritic cells: new implications for atherosclerosis," Atherosclerosis, vol. 172, no. 1, pp. 85-93, 2004.

[48] D. Sun and G. Fernandes, "Lovastatin inhibits bone marrowderived dendritic cell maturation and upregulates proinflammatory cytokine production," Cellular Immunology, vol. 223, no. 1, pp. 52-62, 2003.

[49] S. von Haehling, J. C. Schefold, E. Jankowska et al., "Leukocyte redistribution: effects of beta blockers in patients with chronic heart failure," PLoS ONE, vol. 4, no. 7, Article ID e6411, 2009.

[50] Y. Jo, T. Anzai, Y. Sugano et al., "Early use of beta-blockers attenuates systemic inflammatory response and lung oxygenation impairment after distal type acute aortic dissection," Heart and Vessels, vol. 23, no. 5, pp. 334-340, 2008.

[51] N. Lapteva, K. Ide, M. Nieda et al., "Activation and suppression of renin-angiotensin system in human dendritic cells," Biochemical and Biophysical Research Communications, vol. 296, no. 1, pp. 194-200, 2002.

[52] A. Poggi, A. Rubartelli, and M. R. Zocchi, "Involvement of dihydropyridine-sensitive calcium channels in human dendritic cell function," Journal of Biological Chemistry, vol. 273, no. 13, pp. 7205-7209, 1998.

[53] A. Rubartelli, A. Poggi, and M. R. Zocchi, "The selective engulfment of apoptotic bodies by dendritic cells is mediated by the $\alpha v \beta 3$ integrin and requires intracellular and extracellular calcium," European Journal of Immunology, vol. 27, no. 8, pp. 1893-1900, 1997.

[54] B. Gomes, M. D. Cabral, A. Gallard et al., "Calcium channel blocker prevents Thelper type 2 cell-mediated airway inflammation," American Journal of Respiratory and Critical Care Medicine, vol. 175, no. 11, pp. 1117-1124, 2007.

[55] Y. V. Bobryshev and R. S. Lord, "Ultrastructural recognition of cells with dendritic cell morphology in human aortic intima. Contacting interactions of vascular dendritic cells in athero-resistant and athero-prone areas of the normal aorta," Archives of Histology and Cytology, vol. 58, no. 3, pp. 307-322, 1995.

[56] Y. V. Bobryshev and R. S. Lord, "S-100 positive cells in human arterial intima and in atherosclerotic lesions," Cardiovascular Research, vol. 29, no. 5, pp. 689-696, 1995.

[57] Y. V. Bobryshev and R. S. A. Lord, "Langhans cells of human arterial intima: uniform by stellate appearance but different by nature,” Tissue \& Cell, vol. 28, no. 2, pp. 177-194, 1996.

[58] Y. V. Bobryshev and R. S. Lord, "Structural heterogeneity and contacting interactions of vascular dendritic cells in early atherosclerotic lesions of the human aorta," Journal of Submicroscopic Cytology and Pathology, vol. 28, no. 1, pp. 4960, 1996.

[59] Y. V. Bobryshev, "Dendritic cells and their involvement in atherosclerosis," Current Opinion in Lipidology, vol. 11, no. 5, pp. 511-517, 2000.

[60] Y. V. Bobryshev, T. Ikezawa, and T. Watanabe, "Formation of Birbeck granule-like structures in vascular dendritic cells in human atherosclerotic aorta. Lag-antibody to epidermal Langerhans cells recognizes cells in the aortic wall," Atherosclerosis, vol. 133, no. 2, pp. 193-202, 1997.

[61] Y. V. Bobryshev, R. S. Lord, S. Rainer, O. S. Jamal, and V. F. Munro, "Vascular dendritic cells and atherosclerosis," Pathology Research and Practice, vol. 192, no. 5, pp. 462-467, 1996.

[62] Y. V. Bobryshev and R. S. Lord, " $55-\mathrm{kD}$ actin-bundling protein (p55) is a specific marker for identifying vascular dendritic cells," Journal of Histochemistry and Cytochemistry, vol. 47, no. 11, pp. 1481-1486, 1999.

[63] E. J. Soilleux, L. S. Morris, J. Trowsdale, N. Coleman, and J. J. Boyle, "Human atherosclerotic plaques express DC-SIGN, a novel protein found on dendritic cells and macrophages," Journal of Pathology, vol. 198, no. 4, pp. 511-516, 2002.

[64] A. Yilmaz, T. Fuchs, B. Dietel et al., "Transient decrease in circulating dendritic cell precursors after acute stroke: potential recruitment into the brain," Clinical Science, vol. 118, no. 2, pp. 147-157, 2010.

[65] A. Yilmaz, M. Lochno, F. Traeg et al., "Emergence of dendritic cells in rupture-prone regions of vulnerable carotid plaques," Atherosclerosis, vol. 176, no. 1, pp. 101-110, 2004.

[66] A. Yilmaz et al., "Higher frequency of inflammatory cells, chemokines and chemokine receptors in the upstream shoulder of atherosclerotic plaques," European Heart Journal, p. 457, 2006.

[67] C. Erbel, K. Sato, F. B. Meyer et al., "Functional profile of activated dendritic cells in unstable atherosclerotic plaque," Basic Research in Cardiology, vol. 102, no. 2, pp. 123-132, 2007.

[68] Y. V. Bobryshev, "Dendritic cells and their role in atherogenesis," Laboratory Investigation, vol. 90, no. 7, pp. 970-984, 2010.

[69] E. A. van Vré, J. M. Bosmans, I. van Brussel et al., "Immunohistochemical characterisation of dendritic cells in human atherosclerotic lesions: possible pitfalls," Pathology, vol. 43, no. 3, pp. 239-247, 2011.

[70] A. Niessner, K. Sato, E. L. Chaikof, I. Colmegna, J. J. Goronzy, and C. M. Weyand, "Pathogen-sensing plasmacytoid dendritic cells stimulate cytotoxic T-cell function in the atherosclerotic plaque through interferon- $\alpha$," Circulation, vol. 114, no. 23, pp. 2482-2489, 2006.

[71] A. Niessner, K. Sato, E. Chaikof, J. J. Goronzy, and C. M. Weyand, "Regulation of inflammatory activation in the atherosclerotic plaque: sensitizing effect of type I interferon," European Heart Journal, p. 458, 2006. 
[72] A. Niessner, M. S. Shin, O. Pryshchep, J. J. Goronzy, E. L. Chaikof, and C. M. Weyand, "Synergistic proinflammatory effects of the antiviral cytokine interferon- $\alpha$ and toll-like receptor 4 ligands in the atherosclerotic plaque," Circulation, vol. 116, no. 18, pp. 2043-2052, 2007.

[73] A. Yilmaz, B. Lipfert, I. Cicha et al., "Accumulation of immune cells and high expression of chemokines/chemokine receptors in the upstream shoulder of atherosclerotic carotid plaques," Experimental and Molecular Pathology, vol. 82, no. 3, pp. 245-255, 2007.

[74] Y. V. Bobryshev and R. S. A. Lord, "Mapping of vascular dendritic cells in atherosclerotic arteries suggests their involvement in local immune-inflammatory reaction," Cardiovascular Research, vol. 37, no. 3, pp. 799-810, 1998.

[75] Y. V. Bobryshev and R. S. A. Lord, "Expression of heat shock protein-70 by dendritic cells in the arterial intima and its potential significance in atherogenesis," Journal of Vascular Surgery, vol. 35, no. 2, pp. 368-375, 2002.

[76] I. Kawahara, N. Kitagawa, K. Tsutsumi, I. Nagata, T. Hayashi, and T. Koji, "The expression of vascular dendritic cells in human atherosclerotic carotid plaques," Human Pathology, vol. 38, no. 9, pp. 1378-1385, 2007.

[77] E. A. van Vré, H. Bult, V. Y. Hoymans, V. F. I. van Tendeloo, C. J. Vrints, and J. M. Bosmans, "Human C-reactive protein activates monocyte-derived dendritic cells and induces dendritic cell-mediated T-cell activation," Arteriosclerosis, Thrombosis, and Vascular Biology, vol. 28, no. 3, pp. 511-518, 2008.

[78] G. Millonig, H. Niederegger, W. Rabl et al., "Network of vascular-associated dendritic cells in intima of healthy young individuals," Arteriosclerosis, Thrombosis, and Vascular Biology, vol. 21, no. 4, pp. 503-508, 2001.

[79] Y. V. Bobryshev, W. Cao, M. C. Phoon et al., "Detection of Chlamydophila pneumoniae in dendritic cells in atherosclerotic lesions," Atherosclerosis, vol. 173, no. 2, pp. 185-195, 2004.

[80] Y. V. Bobryshev, R. S. Lord, S. P. Rainer, and V. F. Munro, "VCAM-1 expression and network of VCAM-1 positive vascular dendritic cells in advanced atherosclerotic lesions of carotid arteries and aortas," Acta Histochemica, vol. 98, no. 2, pp. 185-194, 1996.

[81] A. Melián, Y. J. Geng, G. K. Sukhova, P. Libby, and S. A. Porcelli, "CD1 expression in human atherosclerosis: a potential mechanism for T cell activation by foam cells," American Journal of Pathology, vol. 155, no. 3, pp. 775-786, 1999.

[82] V. Y. Hoymans, J. M. Bosmans, D. Ursi et al., "Immunohistostaining assays for detection of Chlamydia pneumoniae in atherosclerotic arteries indicate cross-reactions with nonchlamydial plaque constituents," Journal of Clinical Microbiology, vol. 42, no. 7, pp. 3219-3224, 2004.

[83] A. Yilmaz, B. Lipfert, I. Cicha et al., "Accumulation of immune cells and high expression of chemokines/chemokine receptors in the upstream shoulder of atherosclerotic carotid plaques," Experimental and Molecular Pathology, vol. 82, no. 3, pp. 245-255, 2007.

[84] A. Yilmaz, A. Rowley, D. J. Schulte et al., "Activated myeloid dendritic cells accumulate and co-localize with $\mathrm{CD}^{+} \mathrm{T}$ cells in coronary artery lesions in patients with Kawasaki disease," Experimental and Molecular Pathology, vol. 83, no. 1, pp. 93103, 2007.

[85] L. J. Zhou, R. Schwarting, H. M. Smith, and T. F. Tedder, "A novel cell-surface molecule expressed by human interdigitating reticulum cells, Langerhans cells, and activated lymphocytes is a new member of the Ig superfamily," Journal of Immunology, vol. 149, no. 2, pp. 735-742, 1992.
[86] W. Cao, S. H. Lee, and J. Lu, "CD83 is preformed inside monocytes, macrophages and dendritic cells, but it is only stably expressed on activated dendritic cells," Biochemical Journal, vol. 385, no. 1, pp. 85-93, 2005.

[87] O. Pryshchep, W. Ma-Krupa, B. R. Younge, J. J. Goronzy, and C. M. Weyand, "Vessel-specific toll-like receptor profiles in human medium and large arteries," Circulation, vol. 118, no. 12, pp. 1276-1284, 2008.

[88] R. S. Lord and Y. V. Bobryshev, "Clustering of dendritic cells in athero-prone areas of the aorta," Atherosclerosis, vol. 146, no. 1, pp. 197-198, 1999.

[89] G. Millonig, G. T. Malcom, and G. Wick, "Early inflammatory-immunological lesions in juvenile atherosclerosis from the Pathobiological Determinants of Athero-sclerosis in Youth (PDAY)-study," Atherosclerosis, vol. 160, no. 2, pp. 441448, 2002.

[90] M. Waltner-Romen, G. Falkensammer, W. Rabl, and G. Wick, "A previously unrecognized site of local accumulation of mononuclear cells: the vascular-associated lymphoid tissue," Journal of Histochemistry and Cytochemistry, vol. 46, no. 12, pp. 1347-1350, 1998.

[91] G. Millonig, C. Schwentner, P. Mueller, C. Mayerl, and G. Wick, "The vascular-associated lymphoid tissue: a new site of local immunity," Current Opinion in Lipidology, vol. 12, no. 5, pp. 547-553, 2001.

[92] C. Weber, A. Schober, and A. Zernecke, "Chemokines: key regulators of mononuclear cell recruitment in atherosclerotic vascular disease," Arteriosclerosis, Thrombosis, and Vascular Biology, vol. 24, no. 11, pp. 1997-2008, 2004.

[93] M. Weis, C. L. Schlichting, E. G. Engleman, and J. P. Cooke, "Endothelial determinants of dendritic cell adhesion and migration: new implications for vascular diseases," Arteriosclerosis, Thrombosis, and Vascular Biology, vol. 22, no. 11, pp. 1817-1823, 2002.

[94] E. Galkina, A. Kadl, J. Sanders, D. Varughese, I. J. Sarembock, and K. Ley, "Lymphocyte recruitment into the aortic wall before and during development of atherosclerosis is partially L-selectin dependent," Journal of Experimental Medicine, vol. 203, no. 5, pp. 1273-1282, 2006.

[95] J. Jongstra-Bilen, M. Haidari, S. N. Zhu, M. Chen, D. Guha, and M. I. Cybulsky, "Low-grade chronic inflammation in regions of the normal mouse arterial intima predisposed to atherosclerosis," Journal of Experimental Medicine, vol. 203, no. 9, pp. 2073-2083, 2006.

[96] P. Liu, Y. R. A. Yu, J. A. Spencer et al., "CX3CR1 deficiency impairs dendritic cell accumulation in arterial intima and reduces atherosclerotic burden," Arteriosclerosis, Thrombosis, and Vascular Biology, vol. 28, no. 2, pp. 243-250, 2008.

[97] B. Ludewig and J. D. Laman, "The in and out of monocytes in atherosclerotic plaques: balancing inflammation through migration," Proceedings of the National Academy of Sciences of the United States of America, vol. 101, no. 32, pp. 11529$11530,2004$.

[98] Z. Shaposhnik, X. Wang, M. Weinstein, B. J. Bennett, and A. J. Lusis, "Granulocyte macrophage colony-stimulating factor regulates dendritic cell content of atherosclerotic lesions," Arteriosclerosis, Thrombosis, and Vascular Biology, vol. 27, no. 3, pp. 621-627, 2007.

[99] L. Perrin-Cocon, F. Coutant, S. Agaugué, S. Deforges, P. André, and V. Lotteau, "Oxidized low-density lipoprotein promotes mature dendritic cell transition from differentiating monocyte," Journal of Immunology, vol. 167, no. 7, pp. 3785-3891, 2001.

[100] E. Ibeas, L. Fuentes, R. Martín, M. Hernández, and M. L. Nieto, "Secreted phospholipase $\mathrm{A}_{2}$ type IIA as a mediator 
connecting innate and adaptive immunity: new role in atherosclerosis," Cardiovascular Research, vol. 81, no. 1, pp. 54-63, 2009.

[101] R. Zhang, L. Becnel, M. Li, C. Chen, and Q. Yao, "C-reactive protein impairs human $\mathrm{CD} 14^{+}$monocyte-derived dendritic cell differentiation, maturation and function," European Journal of Immunology, vol. 36, no. 11, pp. 2993-3006, 2006.

[102] L. H. Shen, L. Zhou, B. Y. Wang et al., "Oxidized low-density lipoprotein induces differentiation of RAW264.7 murine macrophage cell line into dendritic-like cells," Atherosclerosis, vol. 199, no. 2, pp. 257-264, 2008.

[103] E. Trogan, J. E. Feig, S. Dogan et al., "Gene expression changes in foam cells and the role of chemokine receptor CCR7 during atherosclerosis regression in ApoE-deficient mice," Proceedings of the National Academy of Sciences of the United States of America, vol. 103, no. 10, pp. 3781-3786, 2006.

[104] J. Llodrá, V. Angeli, J. Liu, E. Trogan, E. A. Fisher, and G. J. Rendolph, "Emigration of monocyte-derived cells from atherosclerotic lesions characterizes regressive, but not progressive, plaques," Proceedings of the National Academy of Sciences of the United States of America, vol. 101, no. 32, pp. 11779-11784, 2004.

[105] T. M. Doherty, E. A. Fisher, and M. Arditi, "TLR signaling and trapped vascular dendritic cells in the development of atherosclerosis," Trends in Immunology, vol. 27, no. 5, pp. 222-227, 2006.

[106] V. Angeli, J. Llodrá, J. X. Rong et al., "Dyslipidemia associated with atherosclerotic disease systemically alters dendritic cell mobilization," Immunity, vol. 21, no. 4, pp. 561-574, 2004.

[107] I. Chereshnev, E. Trogan, S. Omerhodzic et al., "Mouse model of heterotopic aortic arch transplantation," Journal of Surgical Research, vol. 111, no. 2, pp. 171-176, 2003.

[108] E. D. Reis, J. Li, Z. A. Fayad et al., "Dramatic remodeling of advanced atherosclerotic plaques of the apolipoprotein Edeficient mouse in a novel transplantation model," Journal of Vascular Surgery, vol. 34, no. 3, pp. 541-547, 2001.

[109] G. J. Randolph, K. Inaba, D. F. Robbiani, R. M. Steinman, and W. A. Muller, "Differentiation of phagocytic monocytes into lymph node dendritic cells in vivo," Immunity, vol. 11, no. 6, pp. 753-761, 1999.

[110] W. M. Krupa, M. Dewan, M. S. Jeon et al., "Trapping of misdirected dendritic cells in the granulomatous lesions of giant cell arteritis," American Journal of Pathology, vol. 161, no. 5, pp. 1815-1823, 2002.

[111] E. L. Gautier, T. Huby, J. L. Witztum et al., "Macrophage apoptosis exerts divergent effects on atherogenesis as a function of lesion stage," Circulation, vol. 119, no. 13, pp. 1795-1804, 2009. 


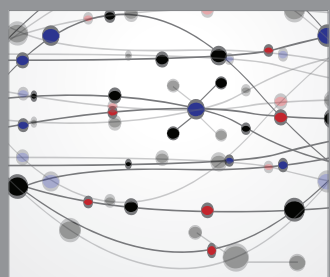

The Scientific World Journal
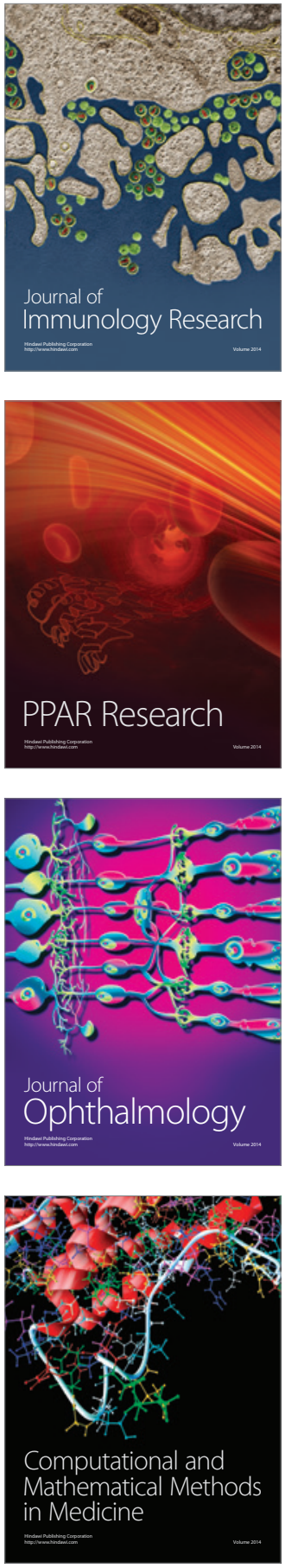

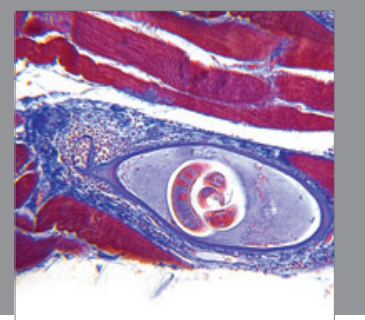

Gastroenterology

Research and Practice
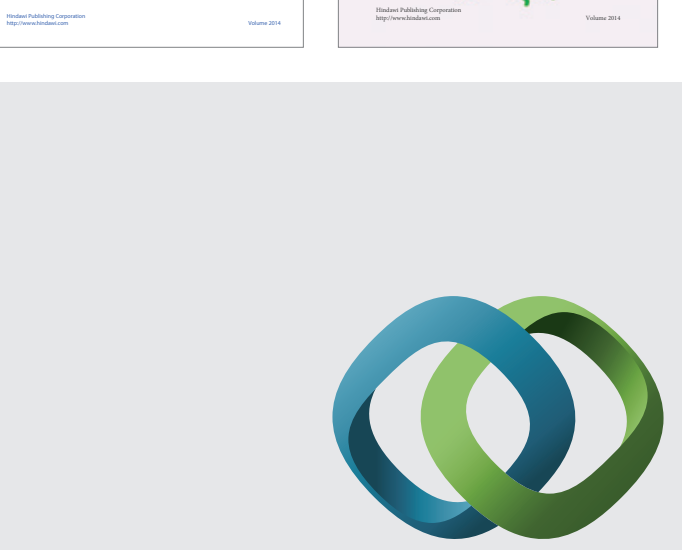

\section{Hindawi}

Submit your manuscripts at

http://www.hindawi.com
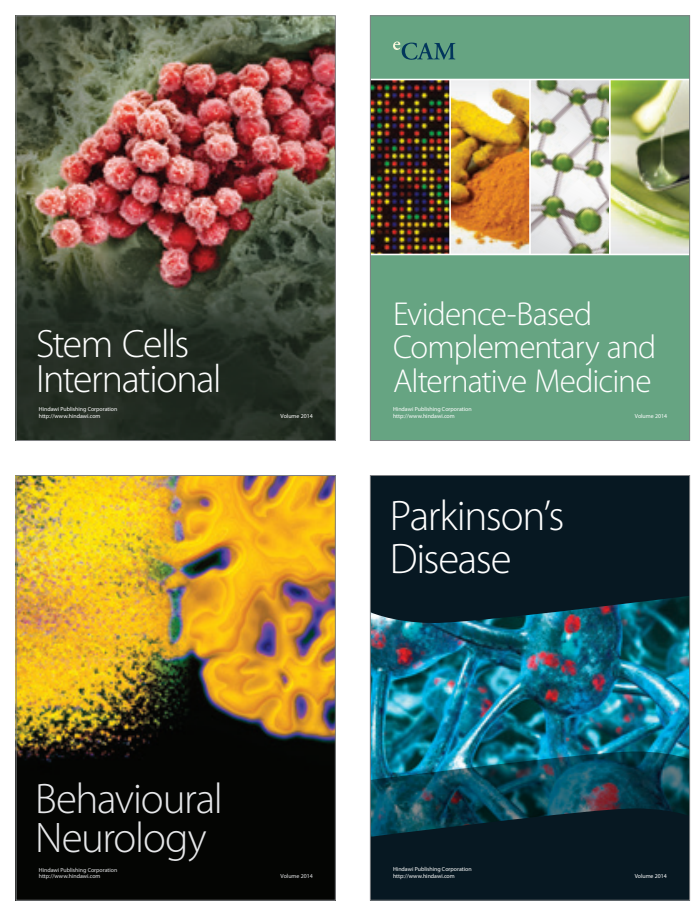

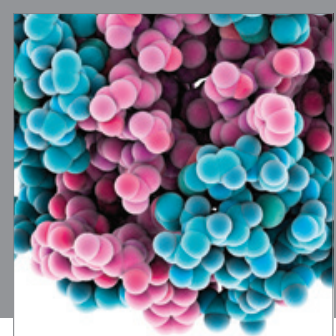

Journal of
Diabetes Research

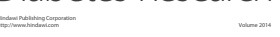

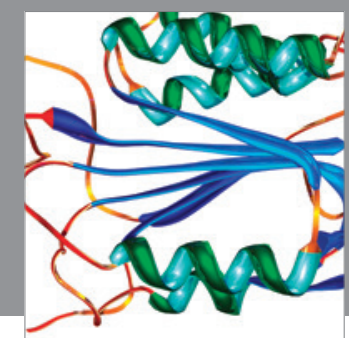

Disease Markers
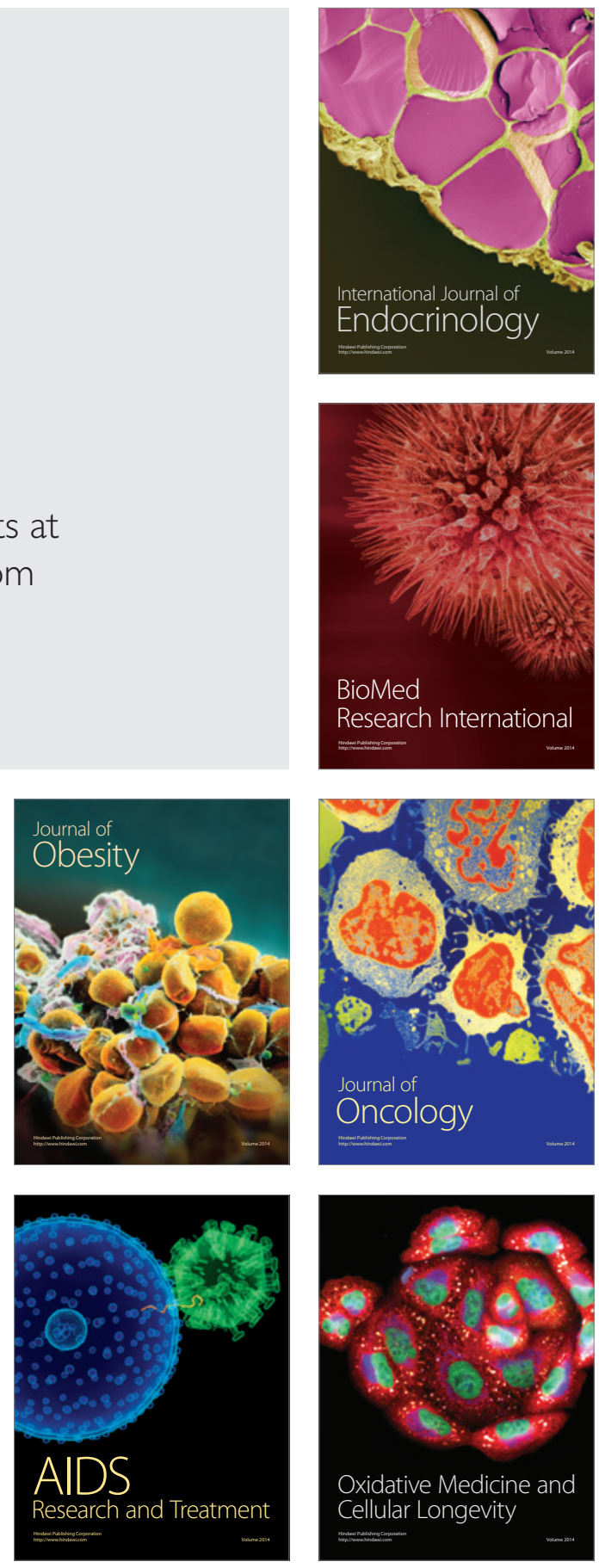